LETTER FROM PHILADELPHIA.

(IROM OUK OWN CORRESPONIDENT.)

Eilection at the Conenty Medical Socicty--Resolutions in Regard to the International Congress-Dr. Le'ris's Address before the Academy of Sungory-Col. Waring's Address on the Disposal of Senvage-Discussion on Pastcur's Treatme'nt of Hydropholia.

The last business meeting of our County Medical Society was, as your occasional correspondent "Spectator" has said, one of great interest. It was an unusually large meeting, because of the anticipated contest over the election of delegates to the State Society, and to the Amerigan Medical Association. It was well recognized that the election of the delegates proposed by the nominating committee would be taken to mean that the Society approved of the action of the Association at New Orleans in regard to the proposed International Congress, and that it endorsed the man who is considered here as the representative of all that that action implied. It was equally well understood that the election of the informally presented candidates would mean that the Society did not approve of what the Association has done, and will not endorse those who furthered it. 'There was a great deal of excitement at the meeting, and it was apparent that all present felt the importance of the vote which was to be taken. Before it was reached there arose a question of law. (On the one hand the rules of the Socicty were cited, and it was claimed that no candidates conld be considered as eligible except those proposed in the usual way by the nominating committee. On the other hand it was replied that, if this were the case, the Society would not annually go through the farce of an election, the mere fact of holding an election implying that the voters could exercise a choice at the polls. In addition to this, it was claimed that the list proposed by the nominating committee was but part of a report, and that the Society could treat this report like any other, altering or amending it, as, for example, by substituting other names for those proposed, if it saw fit. Under this claim a motion was put and carried to substitute for the names on the ticket selected by the nominating committee another set of names, the same as were printed on the new list, which had been sent by mail to the members of the Society.

'The vote in favor of this motion was about three to one, and showed pretty plainly the sense of the meeting. While the voting was proceeding, Dr. $\mathrm{Ag}$ new proposed the following resolutions, which were adopted:

Resolved, That at its annual election of delegates to the American Medical $\Lambda$ ssociation and to the Medical Society of the State of Pennsylvania, the Philadelphia County Medical Society desires to express its regret at the action of the Americin Medi. cal Association at New Orleans, in view of the injurious results which have followed to professional harmony and to the prospects of the International Congress.

Resolved, 'That the delegates from this Society be instructed to endeavor to procure such modification of that action as may best conduce to the reëstal)lishment of professional harmony and to the success of the Congress.

The result of the election was that the new ticket was chosen by the overwhelming vote of 169 votes as against $3^{6}$ for the ticket of the nominating committee.

The annual address before the Academy of Surgery was delivered on January 4 by I)r. Levis, who selected for his subject Impediments to American Surgrery. Of these, he mentioned lack of organized effort, and loss of unrecorded work. In this connection he urged a hearty support of the Committee on Collective Investigation appointed at the last International Medical Congress. He also referred to the reprinting of foreign works at a lower price than native medical works can be produced, and advocated the passage of an international copyright to protect our own authors. 'The value of the American text-books is to be seen from the fact that, in spite of the influence of local jealousy, in 72 colleges, there are recommended to the students $157 \mathrm{Ameri}$ can works on surgery as against 186 foreign works; and he mentioned with pride that of the American works there are three more in demand than any others, and these are all by lellows of the Philadelphia Academy of Surgery. Dr. I,evis also made a plea for the encouragement of the labors of men who live at a distance from the cities. He mentioned the achievements of McDowell, $\Lambda$ tlee, and Sims, as indications of what may be accomplished at a distance from what are generally regarded as the best places for advances in surgery. A considerable part of the address was devoted to discussing the opposition to experiments on the lower animals. Here 1)r. Levis was severe enough on the antivivisectionists. Within a few days Col. Waring addressed the College of Physicians on The Disposal of Srzeage. He presented his now well-known views in regard to this matter, illustrating the successful working of surface disposal of sewage by the case of the Norristown Hospital for the Insane, in this State, and on the edge of this city, where the entire sewage is carried, separate from the surface water, through pipes to a tank which communicates with a field 1000 feet feet away, where it is distributed over the surface. By this process the land is fertilized and the sewage is disinfected.

The last conversational meeting of the County Medical Society was occupied with a discussion of the method of treating hydropholia recently announced by Pasteur. The paper of the evening was read by Ir. Dulles, who gave a summary of all of Pasteur's communications on the subject of hydrophobia, and endeavored to show that the evidence adduced from time to time by Pasteur in support of his various theories does not recommend them very strongly. He laid great stress upon the apparent contradictions of Pasteur's own statements, and the inconsistencies of his conduct; as, for example, when he asserted two years ago that he had a way of rendering dogs refractory to rabies in as large numbers as any one could wish, and yet has not rendered a single dog refractory to rabies outside of his laboratory 
in all that time. He called attention also to the fact that Pasteur's theories in regard to hydrophobia are in striking contrast to his theories in regard to other diseases which he considers to be like it in nature, such as charlom, and chicken cholera. The aim of the whole paper was to convict Pasteur of drawing illogical conchusions from imperfect premises.

1.)r. S. W. (Gross thought that 1)r. Dulles did not do justice to Pasteur, and that he might be assumed to know what hydrophobia is, because there is a large veterinary school near l'aris, l'rance, to which he might be supposed to go to study the disease. He also claimed that l'asteur has protected dogs from inoculation with rabies, and it was safe to suppose he might protect human beings. 'I'o this I)r. l)ulles replied that it might be reasonable to assume that l'asteur knows what rabies is, if he had not put on record some of the symptoms "1pon which he rests his diagnosis. But, he has clone this, and has made it clear that his ideas as to the disorder are much too elastic, and liable to lead to error when applied by such an enthusiast as he is. As to the protection of dogs by inoculation, he referred to the fact spoken of in his paper, that in the past two years this ability which P'asteur claims has proved nothing but a cuuestionable scientific curiosity. The most that can be substantiated for it is that Pasteur seems to be able to fortify the subjects of his experiments against the artificial disease which his virus produces in unvaccinated dogs.

Dr. Wood suggested that there must be a great deal of truth in what Pasteur claims unless we are to suppose his brain is undergoing the inevitable change. 'To this Dr. Julles did not ayree, saying that a man might be very wise in general and yet mistaken as to a special matter. This he thought to be the case with Pasteur, and he hopes it was not necessary to choose between considering him right in regard to hydrophobia, or cra\%y. It may be remarked that the sentiment here seems to be that Pasteur's claims are extravagant and entirely unproved; and we have not had any suggestion of the excitement which had been stirred up elsewhere about hydrophobia in animals or in men.

c. W. 1).

\section{MEMBERSHIP OF THE INTERNATIONAL}

\section{CONGRESS.}

To THE EDTOR OF THE JOURNAI:

Duar Sir.- While the International Medical Congress is being so vigorously discussed in the journals, it is possible the rank and file of the profession are being misled as to what was really expected of them by the Original Committe' of Sirien.

Some months ago the N. Y. Medical Record published a letter from Professor Hansen-Grut, of Hummellaft, Denmark, to I)r. H. D. Noyes, of New York, containing the following statements in reply to inquiries made by Dr. Noyes of him as SecretaryGeneral of the Eighth International Medical Congress, as to the "admissibility of homoeopaths:"

(3). "The only qualification required was that the member be a legally acknowoledged medical practi. tioner in his country. Ou hom(eopathists, who were legally acknowledged practitioners (Drs. Siemsen, Ferich, and others), were actually members, and unclisputed nembers, of mir Congress."

Now let us clearly understand what is expected of us. First. Is it expected that our homoeopathists, who are also "legally acknowledged" practitioners in this country (1)r. Verdi, of Washington, member of the National Board of Health, for example), shall likewise have the right to become "actually members and undisputed members" of the Ninth International Congress, as Professor Hansen-(irut says was the case at the Eighth at Copenhagen?

Sicondly. Is it expected that their homouopathists (1)rs. Siemsen, ferich, and others) being "legally acknowledged practitioners" in their comtry, shall become "actually members and undisputed members" of our Congress, as Dr. Himsen-(irut declares they were of the lighth?

Thirdly. If homeropathists are thus to be admitted to undisputed membership, is it also expected that the other ligally acknoniledged practitioners of this country, who belong to the eclectic, the physiomedical, the hygeio-therapeutic, and the mixed schools included in the enumeration of the legally acknowledged institutions in the United States, in the Report on Medical Education of the Illinois State l3oard of Health for $188_{5}$, shall likewise be actually admitted?

Now, what the members of the American Medical Association want to plainly understand is, whether the doors of the Congress are to be opened to all legally acknosiledsed practitiont's whomsoever in this country. They can then decicle at their approaching ammual meeting just what to do. Meanwhile, perhap's I)r. 13illings, as Secretary of the Original Committee of Seven, ean explain what he and his Committee really did expect of the American Med. ical Association.

A. M. A.

\section{BOOK REVIEWS.}

The Physician Himsile anl, what he Shovid, AIn TO HIS ScIENTIFIC ACQUIREMIENTS IN ORDER to Srcuke Success. By D. W. CAтhri,, M.D., late Professor of Pathology in the College of Physicians and Surgeons of Baltimore. 8vo, pp. 284. Fifth edition. 'Thoronghly revised. Baltimore: Cushings \& laailey, $\quad 1885$.

The appearance of a fifth edition of this volume shows that it is well known and its merits fully appreciated. Consequently no extended notice is necessary. The work is more particularly valuable to the younger members of the profession, and cannot be carefully read without interest and profit. Its style is pleasing, and the statements inculcated are ennobling to the moral character, and calculated to inspire a higher sense of the true dignity of the med. ical profession. 'The publishers have executed their part of the work in good style. 